\title{
The Local Migration of Plant-Based Medicines from Rural Communities to Gral. E. Aquino, Paraguay
}

\author{
Noah Goyke1, Blair Orr ${ }^{2 *}$ \\ ${ }^{1}$ Warnell School of Forestry and Natural Resources, University of Georgia, Athens, GA, USA \\ ${ }^{2}$ School of Forest Resources and Environmental Science, Michigan Technological University, Houghton, MI, USA \\ Email: *bdorr@mtu.edu
}

How to cite this paper: Goyke, N. and Orr, B. (2018) The Local Migration of Plant-Based Medicines from Rural Communities to Gral. E. Aquino, Paraguay Natural Resources, 9, 429-447. https://doi.org/10.4236/nr.2018.912027

Received: December 8, 2018

Accepted: December 26, 2018

Published: December 29, 2018

Copyright ( $) 2018$ by authors and Scientific Research Publishing Inc. This work is licensed under the Creative Commons Attribution International License (CC BY 4.0).

http://creativecommons.org/licenses/by/4.0/

\section{(c) () Open Access}

\begin{abstract}
Rural Paraguay presents interesting opportunities for investigating the subtle differences in the use of medicinal plants across seasons and the urban versus rural dichotomy in a local setting. This study investigates three aspects of plant-based medicinal use in rural Paraguay: 1) seasonal differences and 2) differences between urban and rural residents and 3) the source of medicinal plants used to treat thirteen common ailments. Interviews performed in January through March 2015 and repeated in June through August 2015 revealed small differences between seasons and between places of residence but a larger homogeneity in the two populations, a homogeneity that stems from the recent migration of urban residents from nearby rural communities. We also found that the important cultural and preventive medicinal use of plant-based additions to yerba mate contributes to the similarities between the urban and rural populations. The findings suggest the continued strength of medicinal plant use going into the near future.
\end{abstract}

\section{Keywords}

Seasonal Use, Importance Values, Yerba Mate, Urban/Rural, Ethnobotany

\section{Introduction}

As plants and people migrate together across large physical and social distances, frequently to more urban settings, one would expect to find adaptation in plant-based medicine use to new and substantially different conditions. Does this pattern hold when the physical and social distances are much more local? As a general hypothesis one expects that as urbanization increases the knowledge 
and use of plant-based medicines declines [1]. Research has demonstrated that first generation immigrants, populations that are migrating or urbanizing, retain ethnobotanical knowledge and continue using some plant-based medicines [2] [3]. However, other research has demonstrated that even regional knowledge of plant based medicine does not outlast urbanization in the long run (e.g. [4]). We examine a district town and a small nearby farming community in eastern Paraguay to observe more localized migration and the use of plant-based medicines to determine the types and magnitudes of change and how local social and cultural factors have influenced the transition.

Rural Paraguay provides a study area with relatively recent and rapid modernization of outlying communities and the corresponding increase in access to pharmaceutical medications. A near freeze on internal movement of the population until the last generation has resulted in a large part of the urban population having recently migrated directly from nearby rural communities [5].

Despite the importance of plant-based medicine as both an essential part of the local healing traditions and an important cultural touchstone, it is understudied in Paraguay [6] [7]. Studies concerning medicinal plants are generally limited to catalogs of plants available in urban markets [8] [9], pharmacological investigations [10] [11], and ethnobotanical studies of indigenous populations in the Gran Chaco region of western Paraguay [12] [13] [14]. Available scholarship rarely considers the ethnobotany of eastern Paraguayan populations, an idea emphasized by Arenas, "casi no existen estudios sobre estos temas ente la población no indígena chaqueña" [there almost do not exist studies about these topics among the non-indigenous Chaco population] [13]. In particular, comparisons between populations in small urban settings and their neighboring rural populations are lacking. Rural is primarily defined by occupation; most residents are engaged in some natural resource occupation, in this case farming, that puts them in close contact with plants on daily basis. Urban implies that most occupations are in manufacturing or service industries. In addition, the urban area had more health and education services, improved infrastructure, and higher population and housing density.

The ethnobotanical literature does a much better job of addressing plant-based medicine and migrations when the focus is on long distance rather than local migrations and the migrations tend to represent migration into a new culture or ecological setting [15]-[20]. The migrations addressed in the literature also are often urban to urban migrations. Some non-migratory comparisons between rural and urban populations [21] or urban ethnopharmacological studies in South America [22] exist in the literature but they tend to focus on specific plants [23] [24] or ailments [25]. Ethnobotanical studies also frequently fail to consider explicitly the role of pharmaceutical medicine in the study population even though the availability of western pharmaceuticals is cited frequently as a cause for decline in plant-based medicine use.

This study investigates the differences in the application rather than knowledge of plant-based medicine between a rural and urban population for thirteen 
common ailments over the summer and winter seasons. That is, a recent migrant may retain knowledge but use pharmaceutical remedies rather than plant-based medicines. Our study was not designed to capture the knowledge base. We were able to examine the differences in the use of plant-based medicines between a rural farming community in decline and a growing town with urban characteristics that are only seven kilometers apart.

We identified 171 plants that are used for medicinal purposes in the study area, although the study also uses a subset of the most common 18 plant species for some of the analysis. Our study includes medicinal plants used when brewing yerba mate (Ilex paraguariensis A. St.-Hil.) tea. Yerba mate is a central part of Paraguayan culture, a culture that is a blend of Spanish and Guarani cultures. Traditional brewing of yerba mate includes plant-based medicines in the steeping process [26].

Based upon proximity, we predicted that both the urban and rural population would be equally likely to experience the same ailments. Community observation prior to initiating the study led us to believe that the number of individual cases of an ailment would increase for both urban and rural populations in the winter season. We also predicted that the urban population would more frequently use pharmaceutical medicines, on a whole having better access, and that pharmaceuticals would be more often used by both populations in the winter season. We predicted that urban residents would be more likely to purchase their medicinal plants than rural residents irrespective of season. However, the easy and equal access to some pharmaceutical medicines, the recent increase in migration, the geographic proximity, and cultural importance of medicinal plants led us to believe that the populations would be more similar than different in their overall use of plant-based medicine.

\section{Methods}

\subsection{Study Area}

The study took place in the rural community of Chamorro Cué (24.275032S, $56.561237 \mathrm{~W}$ ) and neighboring urban center of Gral. E. Aquino (24.263708S, $56.540507 \mathrm{~W}$ ), which is the administrative and service center for many outlying rural communities including Chamorro Cué. The two communities are approximately $7 \mathrm{~km}$ apart and rural community members frequently travel to Gral. E. Aquino for goods and services and to visit family.

Chamorro Cué is a small rural community driven economically by smallholder farming of cash crops including sesame (Sesamum indicum), chia (Salvia hispanica), and sunflowers (Helianthus sp.), in addition to subsistence crops such as corn (Zea mays), manioc (Manihot esculenta) and beans (Phaseolus vulgaris) plus seasonal gardens in the winter. Eighty-six percent of households count farming as their primary source of income. In the two decades prior to this study Chamorro Cué witnessed rapid modernization. In 1996 a community water system and electrical grid were established. By 2000 all homes had access to running 
water and $95 \%$ of homes were connected to the electrical power grid. Since 2000 the population of Chamorro Cué has declined appreciably, from 750 residents to 450 , as people leave the community in search of economic opportunities elsewhere [27]. Paraguayan economic migrants travel as far as Spain [28] and Buenos Aires [29], although many go to the capital of Asunción and even more to nearby towns like Gral. E. Aquino.

Gral. E. Aquino is the municipal center for the district of the same name, and is home to the municipal office, hospital and pharmacies, police and fire headquarters, school superintendence and other services. The community's economy is primarily service driven. Members of nearby rural communities frequently travel to Gral. E. Aquino to take advantage of these services. Our measure of urbanization/migration is the growth of Gral. E. Aquino and the movement of the nearby farming residents to the community. Population data for the urban community of Gral. E. Aquino is not available, but an analysis of aerial photos dating back to 2000 indicate that the geographic area covered by the town has grown by approximately fifty-one percent since then (Figure 1). This growth

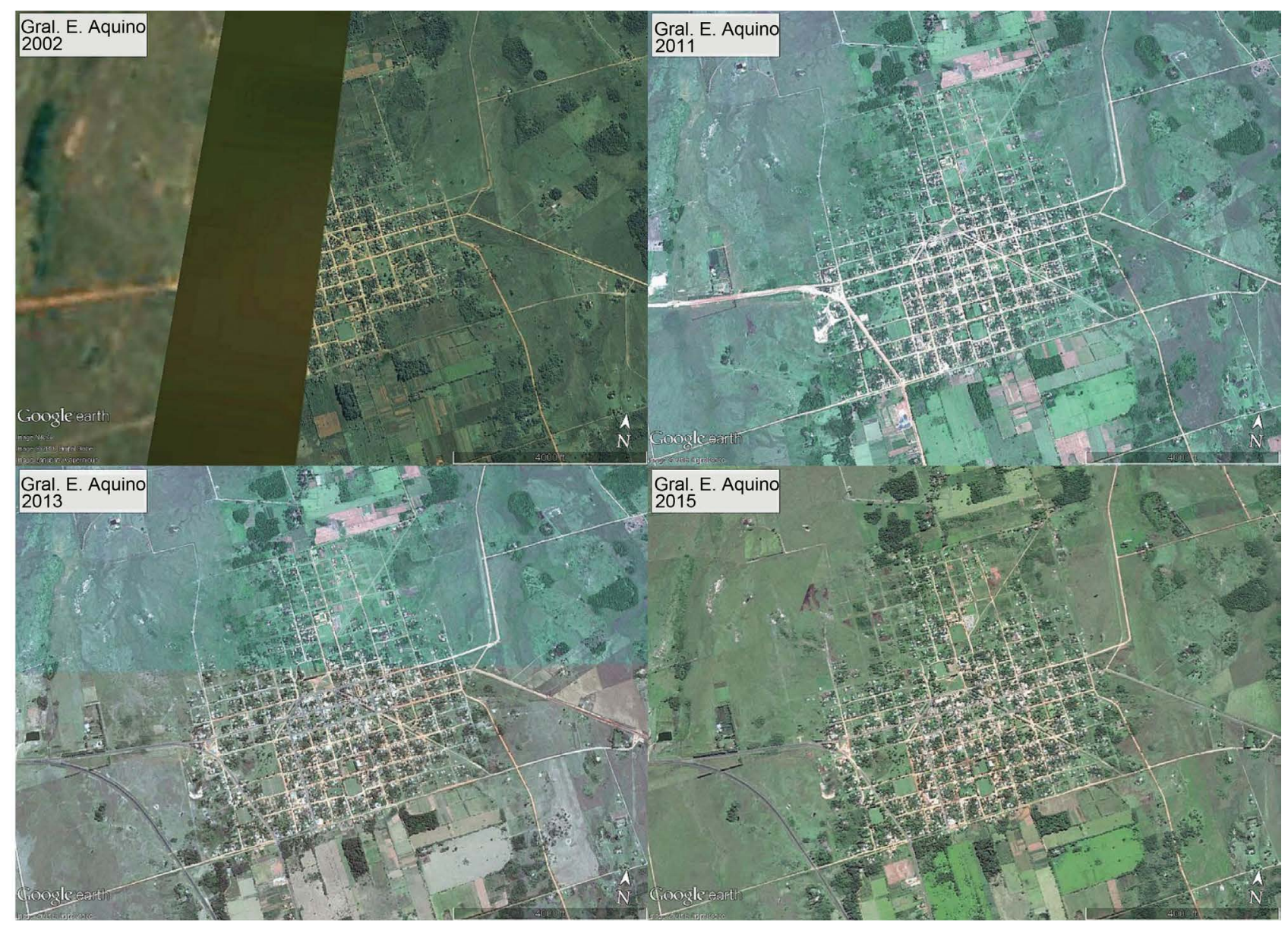

Figure 1. Change in the size of urban center of Gral. E. Aquino from 2002 to 2015. Photo dates: upper left, 2002; upper right, 2011; lower left, 2013; lower right, 2015. The 2002 photo includes a missing strip where satellite imagery did not capture all of Gral. E. Aquino but allows long-term analysis of at least the eastern half of Gral. E. Aquino. (Data and Images: US Dept of State Geographer; 2018 Google Image Landsat/Copernicus). 
contrasts with a mere 3.7 percent population growth for the entire district over the previous decade [30]. Approximately half of the urban participants in this study reported migrating from rural communities. Together the two suggest that local migration is the phenomenon driving the growth of the urban center. The decline of Chamorro Cué and the growth of Gral. E. Aquino is the result of migration to Gral. E. Aquino.

\subsection{Interviews and Ethical Considerations}

Prior to interviews preliminary conversations were held with a subset of the local population to identify the most common ailments experienced by the population. These conversations resulted in a list of thirteen common ailments that formed the basis of the formal interviews. Since the respondents were asked to recall ailments there was no method to confirm ailments or determine causes. As interviews were open ended it did appear that responses were consistent among the community members. Conversations and observations supported by the literature indicated that urban dwellers had a knowledge of and inclination to use plant-based medicine. Conversations, observations, and the diversity of plant species for sale in markets in regional towns like Gral. E. Aquino [8] suggest that the rural and urban population were sufficiently similar in knowledge and practice of plant-based medicine use to be suitable for comparison.

Interviews were conducted with forty-four families in the months of January through March of 2015 and repeated in July and August. Thirty families lived in Chamorro Cué and represent the rural participants in the study. Fourteen families representing urban residents were selected in Gral. E. Aquino. Families were selected as the interview unit to capture the use of diseases across different demographics within a family. For example, in preliminary conversations participants indicated urinary pain affecting men more, parasites affecting children more, and high blood pressure most often effecting the elderly. Both rural and urban households typically included two generations, while rural households generally had more members than urban ones (Table 1). At least one key individual participant was present in both the summer and winter household interviews. Characteristics of the key individual participants are shown in Table 2. It is important to realize that many of the key individual participants had a primary occupation and a secondary occupation, with the blend varying from household to household. Few families relied solely on one occupation. In addition, the interviews captured responses from an entire families, not just the responses of the key individual participants. In general older participants had lower levels of educational attainment.

Table 1. Average family size and number of generations/family for rural and urban families.

\begin{tabular}{ccc}
\hline & Generations & Family Size \\
\hline Rural & $2.10 \pm 0.25$ & $4.13 \pm 0.67$ \\
Urban & $1.79 \pm 0.33$ & $3.29 \pm 0.70$ \\
\hline
\end{tabular}


Table 2. Demographic characteristics of the key individual participants in Gral. E. Aquino (14 people) and Chamorro Cué (30 people).

\begin{tabular}{lccc}
\hline & Chamorro Cué & Gral. E. Aquino & Total \\
\hline Sex & 17 & 8 & 25 \\
Male & 13 & 6 & 19 \\
$\quad$ Female & & & \\
Education & 20 & 1 & 21 \\
$\quad$ Did not complete & & & \\
high school & 10 & 13 & 23 \\
High school or & & & \\
beyond & & & 4 \\
Occupation & 0 & 4 & 9 \\
Extension Agent & 9 & 0 & 9 \\
Farmer & 9 & 0 & 13 \\
Homemaker & 7 & 6 & 9 \\
Teacher & 5 & 4 & \\
Other & & &
\end{tabular}

The interviews took place in participants' homes and were conducted in either Spanish or Guarani. Participants were asked directly about the presence of ailments, and the type and source of remedy used and then engaged in a conversation exploring their ideas about medicinal plant use. Each interview lasted approximately one hour.

Participants gave oral consent as approved by the Michigan Technological University Institutional Review Board (IRB). The IRB format and requirements are consistent with the International Society of Ethnobiology Code of Ethics [31]. The Code of Ethics does recommend written consent but we used oral consent as some of the older participants were more comfortable with this format.

The first author spent two years living and working in the communities of Chamorro Cué and Gral. E. Aquino plus an additional year in Asunción. During those three years he spent hundreds of hours engaged with community members in conversations about everyday topics, including plant-based medicine. $\mathrm{He}$ practiced a lifestyle similar to his neighbors, shared meals with them, and frequently used preventive and curative plant-based medicine in his daily life. The first year living in Chamorro Cué prior to initiating research allowed him to gain an understanding of community concerns and dynamics and to understand sensitive topics. Several years of participant observation by the first author provides additional support for our findings [32].

Most of the plants described and all of the plants commonly used are sold commercially locally and in Asunción. Yerba mate is traded and consumed globally. 


\subsection{Data Analysis}

\subsubsection{Fisher's Exact Test}

Data for the urban and rural populations and as well as seasonal data was analyzed using Fisher's exact test in SAS 9.4 for Windows. Using G*Power the calculated power for this two-tailed Fisher's exact test $\left(\mathrm{n}_{1}=30, \mathrm{n}_{2}=14, \alpha=0.05\right)$ is 0.65 , indicating that the small sample size may lead to accepting a null hypothesis when a larger sample size would have rejected it [33]. There may be more differences than our study indicates. For example, there could be differences in presence or absence of an ailment, type of remedy used (plant-based or pharmaceutical) and the source of medicinal plants (purchased, cultivated, or collected wild) that are not detected due to the small sample size. We define "wild collection" as collection occurring along road sides, brushy or woody areas or in farm fields. That is, wild collection occurs when the plant is not cultivated.

\subsubsection{Relative Importance}

Individual plants were also assigned a relative importance value in order to compare plant use between rural and urban respondents and different seasonal uses. The relative importance concept is adapted from Bennett and Prance [34] and Benítez et al. [8]. Relative Importance is comprised of normalized ailment $(A)$ and response $(R)$ values. The ailment value is the number of ailments for which a plant is mentioned out of the highest number of ailments mentioned for a single plant. Response is total responses for a plant divided by the maximum number of responses for all plants. Relative importance values $\left(R I_{i}\right)$ for each plant i were calculated. Data were analyzed using linear regression to compare difference in seasonal use of specific plants. While $R I$ may underestimate the importance of a plant with just a single use our analysis was done with only the eighteen most important plants, eliminating this problem with $R I$ analysis.

$$
\left(R I_{i}\right)=\frac{\left(R_{i}\right)+\left(A_{i}\right)}{2} \times 100
$$

where

$$
\begin{aligned}
& \left(R I_{i}\right)=\text { Relative Importance of plant } i \\
& \left(R_{i}\right)=\text { Normalized Response Value }\left(R_{i} / R_{\max }\right) \text { for plant } i \\
& \left(A_{i}\right)=\text { Normalized Ailment Value }\left(A_{i} / A_{\max }\right) \text { for plant } i
\end{aligned}
$$

\section{Results and Discussion}

Plant-based medicine use is strikingly similar between the rural and urban populations; medicinal plant use has generally outlasted local migration and urbanization. However, there are several significant differences between how the two populations use medicinal plants and where they obtain their plants. There are also seasonal differences shared by the rural and urban population, particularly in the specific plants used in summer versus winter. Based upon interviews and observation it seems social and cultural factors best explain these differences, rather than environmental and biological factors. This suggests that a funda- 
mental loss of knowledge or change in attitudes does not drive the differences that do exist. We also found that plant-based medicines are incorporated in yerba mate as a preventive measure.

\subsection{Presence vs. Absence of Thirteen Common Ailments}

Differences between the presence of the thirteen common ailments in the rural and urban communities is crucially important to highlight. They demonstrate that social factors, rather than differences in knowledge of or willingness to use plant-based medicine are responsible for some of the most fundamental differences between the urban and rural participants. Participants reported that three of the thirteen common ailments as less frequently present in the urban population: kidney problems, urinary pain, and high blood pressure $(\mathrm{p}<0.0001, \mathrm{p}=$ $0.0171, p=0.0002$ respectively) (Table 3 ). Social factors explain all three of these differences. The medicines taken for kidney problems are typically preventive, diuretic medicine used to control dehydration and hyperhydration. Many participants attributed kidney problems related to hydration and to spending extended periods in the sun, which rural farmers do much more frequently than urban service workers. The logic, according to one farmer, is that it is necessary to hydrate extremely well in the heat, but that there is a danger of having too much water in the body which means the farmers are exposed to kidney problems and must take preventive medicine. Urinary pain is similar to kidney problems because it is associated with spending time in the sun, especially, as the first author was frequently reminded while preparing to work outdoors, without closed toed shoes or long sleeves. Again, it is rural farmers who spend their time out in the sun more often than service workers in Gral. E. Aquino. A pair of

Table 3. Ailment presence by season and place of residence as a percentage of all participants reporting the ailment.

\begin{tabular}{ccccc}
\hline & Summer & Winter & Rural & Urban \\
\hline Cold & 77 & 89 & 87 & 75 \\
Constipation & 66 & 64 & 67 & 61 \\
Cough & 82 & 82 & 85 & 71 \\
Diarrhea & 61 & 73 & 67 & 68 \\
Fever & 75 & 82 & 82 & 71 \\
Headache & 91 & 75 & 83 & 82 \\
High Blood Pres. & 59 & 64 & $75^{*}$ & $32^{\star}$ \\
Kidney & $84^{*}$ & $59^{*}$ & $85^{*}$ & $43^{*}$ \\
Pain & 68 & 68 & 72 & 61 \\
Parasites & 72 & 77 & 72 & 89 \\
Sore Throat & 91 & 89 & 88 & 93 \\
Stomachache & 84 & 80 & 85 & 75 \\
Urinary Pain & 66 & 59 & $80^{*}$ & $43^{*}$ \\
\hline
\end{tabular}

*: significant result $(\mathrm{p}<0.05)$. 
social factors likewise best explain the lower presence of high blood pressure in the urban community: diet and demographics. Rural families tended to include an elderly generation more often than urban families, with the elderly generation defined as those whose generational cohort has grandchildren. Young people are more likely to migrate from the rural community. The first author also observed and conversed with participants in both the rural and urban communities about the rural diet, one higher in salt, sugar, and oil while lower in vegetables. This was especially pronounced in the hot, dry summer when gardens were not generally maintained and produce was prohibitively expensive. It is social factors and lifestyle, rather than any difference in knowledge or aversion to using plant-based medicine that caused these differences. The few differences that do exist highlight the overall similarity between the two populations.

The only pronounced seasonal difference was in the significantly higher presence of kidney problems $(\mathrm{p}=0.0171)$ in the summer. Again, the presences of perceived danger of kidney problems necessitating the use of preventive medicine was attributed to frequent hydration, which is much more common in the hot summer months and more common for farmers. This difference is not the result of knowledge or willingness to use plant-based medicine, but rather a climactic factor and occupation, a socioeconomic factor.

While we had predicted that ailments would be more common in the winter they were generally seasonally similar, and in the few exceptions where the differences were statistically significant the ailment was more common in the summer.

\subsection{Type of Medicine Used to Treat the Thirteen Common Ailments}

The rural and urban populations are similar in their preference for plant-based or pharmaceutical medicine to treat or prevent the thirteen common ailments (Table 4). The data collected included the use of plants that were added to yerba mate tea when respondents specifically mentioned that the plants were included in the tea for the medicinal properties. (The medicinal additions may have a dual role for flavoring.) As drinking yerba mate is a cultural cornerstone in Paraguay, the similarities between rural and urban populations can be partially explained by the use of yerba mate by both populations.

The only ailment for which there is a significant difference between the urban and rural populations in preference for pharmaceutical medicine over medicinal plants is for the treatment of parasites $(\mathrm{p}=0.0431)$. Once again, a social factor is responsible for this difference. Conversations with participants, including three health care professionals, consistently revealed the perception that parasites affect young children more often than adults and with greater detrimental health effects. Most families only reported giving any sort of medication against parasites on a regular basis to children. In Gral. E. Aquino the school system provides anti-parasitical medication to students, but rural participants reported 
Table 4. Medicine type used by rural and urban participants as a percentage of all participants.

\begin{tabular}{ccccccc}
\hline & \multicolumn{3}{c}{ Rural } & & \multicolumn{3}{c}{ Urban } \\
\cline { 2 - 6 } & Pharm. & Natural & Both & Pharm. & Natural & Both \\
\hline Cold & 25 & 46 & 29 & 10 & 38 & 52 \\
Constipation & 10 & 85 & 5 & 0 & 94 & 6 \\
Cough & 14 & 75 & 12 & 25 & 50 & 25 \\
Diarrhea & 15 & 68 & 18 & 21 & 63 & 16 \\
Fever & 51 & 24 & 24 & 60 & 25 & 15 \\
Headache & 64 & 10 & 26 & 83 & 13 & 4 \\
High Blood & 29 & 53 & 18 & 33 & 44 & 22 \\
Pres. & 2 & 94 & 4 & 8 & 92 & 0 \\
Kidney & 65 & 21 & 14 & 71 & 18 & 12 \\
Pain & 21 & 70 & 9 & 48 & 40 & 12 \\
Parasites & 15 & 68 & 17 & 12 & 46 & 42 \\
Sore Throat & 15 & 90 & 4 & 10 & 76 & 14 \\
Stomachache & 6 & 88 & 9 & 17 & 83 & 0 \\
Urinary Pain & 2 & & & &
\end{tabular}

*: significant result $(\mathrm{p}<0.05)$.

consistently that the medication rarely reaches their school, hence the higher percentage of families reporting the use of pharmaceutical medicine use for the urban population. Again, it is a social factor outside the control of the participants that explains the only deviation from the otherwise strong similarity between the two populations.

Apart from anti-parasitical medication, both urban and rural participants reported typically using only inexpensive and readily available over-the-counter pharmaceuticals like acetaminophen and ibuprofen. Families in both the rural and urban area also indicated in conversations that they often give pharmaceutical medication to children even when adults in the family take plant-based medicines. This pattern explains why some families use both pharmaceutical and plant-based medicine, especially in urban areas. Better access accounts for the slightly higher use of pharmaceutical medication among the urban population. Over-the-counter medications are readily available at small rural stores. Other pharmaceutical medications are found at pharmacies that are both physically distant from rural homes and the medications are beyond the economic means of rural farming families who tend to have lower disposable incomes than urban workers.

\subsection{Source of Medicinal Plants Used to Treat the Thirteen Common Ailments}

Many of the most important and most frequently used medicinal plants are not sold dried and preserved. A participant involved in the raising, drying, and sell- 
ing of medicinal plants explained that part is cultural and part is practical. Some plants are almost always collected wild and consumed in the moment or sold fresh. An excellent example is Gomphrena ducumbens Jacq, only once in three years in Paraguay did the first author see it available for sale as a dried specimen. Some plants, for example Matricaria recutita L., are also more amenable to the large-scale production required to make the practice of drying and preserving them profitable. Still, the informal economy of rural plant growers allows urbanites to obtain the most popular medicinal plants either fresh or dried, despite their absence in the urban center itself.

The urban and rural populations followed similar trends in the source of medicinal plants for twelve of thirteen common ailments; although urban participants tend to purchase medicinal plants slightly more and collect them in the wild slightly less than rural participants (Table 5). The source of the medicinal plants used to treat diarrhea varied significantly between the rural and urban populations, rural participants almost never purchase plants to treat diarrhea, while urban participants purchased and cultivated plant-based medicines more than the rural residents. The difference is related to the specific plants used. Unlike some ailments, treatment of diarrhea is concentrated in one specific plant, Pluchea sagittalis (Lam.) Cabrera, and accounts for thirty percent of all treatment; it is a plant that is reported as only collected wild. The inability to find wild $P$. sagittalis in the urban area may drive the differences in source of medicinal plants to treat diarrhea.

Table 5. Medicinal plant source for rural and urban participants as a percentage of all responses.

\begin{tabular}{ccccccc}
\hline & \multicolumn{3}{c}{ Rural } & \multicolumn{3}{c}{ Urban } \\
\cline { 2 - 6 } & Purchased & Cultivated & Wild & Purchased & Cultivated & Wild \\
\hline Cold & 14 & 44 & 42 & 27 & 45 & 27 \\
Constipation & 36 & 36 & 27 & 54 & 38 & 8 \\
Cough & 15 & 40 & 44 & 17 & 35 & 48 \\
Diarrhea & 4 & 32 & 64 & 22 & 44 & 33 \\
Fever & 53 & 8 & 39 & 89 & 0 & 11 \\
Headache & 28 & 32 & 40 & 33 & 33 & 33 \\
High Blood & 4 & 49 & 47 & 0 & 25 & 75 \\
Pres. & 31 & 17 & 53 & 27 & 20 & 53 \\
Kidney & 55 & 20 & 25 & 50 & 17 & 33 \\
Pain & 13 & 16 & 71 & 28 & 17 & 56 \\
Parasites & 9 & 33 & 58 & 18 & 38 & 44 \\
Sore Throat & 95 & 14 & 61 & 42 & 13 & 46 \\
Stomachache & 25 & 35 & 61 & 8 & 50 & 42 \\
Urinary Pain & 3 & & & & & \\
\hline
\end{tabular}

*: significant result $(\mathrm{p}<0.05)$. 
Our findings are generally in line with the overall literature, which indicates that the closer the rural and urban populations (spatially and socio-economically) the more similar their behavior. Urban residents in Suriname also use medicinal plants based upon their familiarity with plant-based medicines and the relatively low cost when compared to pharmaceuticals [22]. In contrast, Garcia et al. [35] found significant differences in plant use among migrants within Brazil. They found that more accessible health care was one reason people shifted to more use of pharmaceutical medicines. In our study health care is closer for our rural population, but still not as accessible as it is for the urban population both because of the travel distance and the urban population in Gral. E. Aquino is somewhat wealthier.

The source of the plant is an important difference between our study and several other studies that investigate short-distance migration [21] [36]. These two studies ask what plant-based medicines are purchased by urban residents and compare that value with use by rural residents. Urban participants were sampled at herbal medicine shops. That technique undercounts urban use. We found that treatments for only three of the thirteen ailments listed in Table 5 had 50\% of the plant-based medicines purchased and significant numbers were either cultivated or gathered in the wild. We find substantially more use of plant-based medicines. In addition, our study method was able to identify more use of plant-based medicines as preventive rather than curative. We are not able to determine if this is due to a difference in survey methods or a difference that exists between our study site and those of the other studies. Migrants in Atlanta, GA, USA did use food with medicinal qualities as a preventive strategy and showed a similar desire to respondents in our study to use both plant-based and pharmaceutical medicines [37]. Residents of Paramaribo, Suriname used bitter tonics as preventive medicine like the Paraguayan use of yerba mate [22].

\subsection{Seasonal Importance of Medicinal Plants Used}

The distribution of the eighteen plants with the highest (RI) values based on their winter and summer (RI) values taken as a whole shows weak correlation (Table 6; Figure 2, all points). However, when the data are disaggregated a strong positive correlation exists between the summer and winter (RI) values for plants with a higher winter (RI) value and a strong negative correlation between summer and winter (RI) value for plants with a higher summer (RI) value. The explanation for the trends lies not in the pharmacological properties of the plants themselves, as was predicted, but instead in the culture of medicinal plant use in Paraguay.

In Paraguay, people often consume either preventive and curative medicinal plants as additives to hot or cold tea of the yerba mate plant. Medicinal plants are key components of the tea, serving both medicinal and flavoring purposes. People drink the tea itself either boiling hot or freezing cold, with many plants added specifically for one drink or the other; strong flavors like anise and 
Table 6. Relative importance of eighteen most important plants, with (A) and (R) values and (RI) values for summer and winter.

\begin{tabular}{|c|c|c|c|c|c|}
\hline & (RI) & (A) & (R) & (RI) Summer & (RI) Winter \\
\hline Citrus $\times$ aurantium & 97 & 100 & 95 & 78 & 91 \\
\hline Pluchea sagittalis & 84 & 69 & 100 & 65 & 78 \\
\hline Matricaria recutita & 80 & 88 & 73 & 65 & 77 \\
\hline Verbena bonariensis & 73 & 81 & 64 & 64 & 65 \\
\hline Eucalyptus sp. & 70 & 50 & 90 & 42 & 75 \\
\hline Pimpinella anisum & 66 & 56 & 76 & 47 & 69 \\
\hline Mentha piperita & 62 & 75 & 49 & 59 & 51 \\
\hline Aloysia polystachya & 59 & 56 & 61 & 66 & 38 \\
\hline Acicarpha tribuloides & 57 & 31 & 83 & 59 & 39 \\
\hline Gomphrena decumbens & 57 & 56 & 58 & 55 & 48 \\
\hline Phyllanthus niruri & 57 & 44 & 69 & 79 & 22 \\
\hline Salvia officinalis & 57 & 44 & 69 & 42 & 54 \\
\hline Psidium guajava & 55 & 44 & 66 & 55 & 41 \\
\hline Artemisia absinthium & 54 & 56 & 53 & 55 & 42 \\
\hline Cecropia pachystachya & 53 & 50 & 56 & 38 & 53 \\
\hline Peumus boldus & 51 & 25 & 76 & 32 & 51 \\
\hline Chenopodium ambrosioides & 50 & 50 & 51 & 62 & 28 \\
\hline Dorstenia brasiliensis & 50 & 31 & 69 & 45 & 42 \\
\hline
\end{tabular}

chamomile are generally preferred in the hot tea while smooth flavors like mint and lemongrass are preferred in the cold. Most medicinal plants are strongly associated with one tea temperature or the other. So important is the distinction between the hot and cold teas that different Guarani verbs are used to describe drinking them cold (aterere) and hot (akay'u).

People drink the hot tea in the winter season, which explains why some plants have higher winter values. However, many families also drink the hot tea year-round in the early hours of the morning before breakfast, which explains why the relative importance of these plants remains high though the summer months. People drink the cold tea in the summer months, hence the plants with high relative importance in the summer, but its consumption is, at most, intermittent in the cold winter months, which explains the strong negative correlation between the (RI) values of plants that are more important in the summer than they are winter.

The eighteen most important plants include some plants that are native and some that are exotic. Plant types in the 18 most important species range from trees and shrubs to annual forbs and grasses. People make use of a wide variety of plants to meet their medicinal needs. All eighteen of the most important plants are used in the preparation of yerba mate but may also be consumed or used in other ways. 


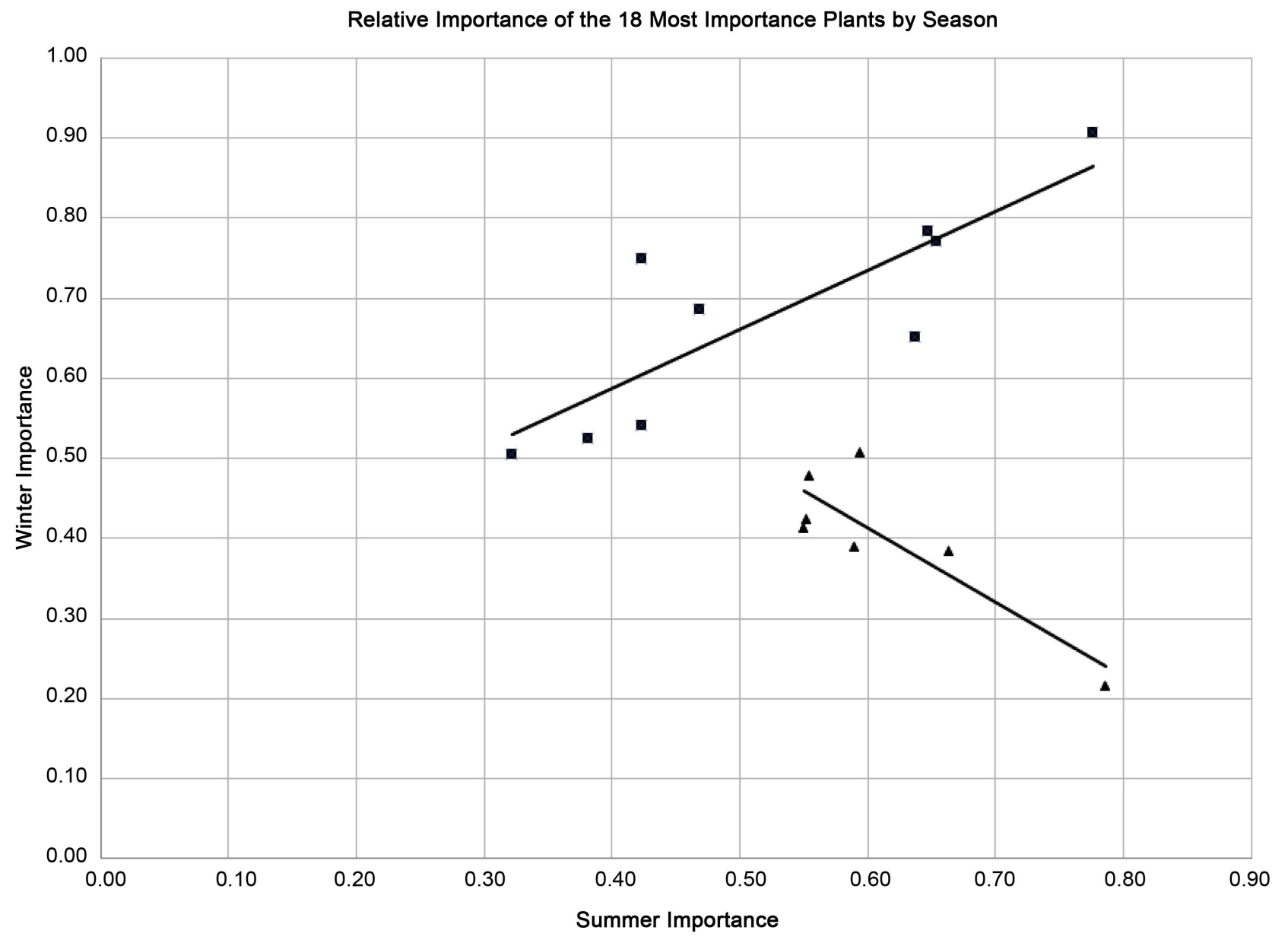

Figure 2. Distribution of the 18 plants with the highest (RI) by Winter (RI) and Summer (RI) values, and series defined by greater Summer (RI) or Winter (RI) values. When all points are considered there is weak correlation, but when disaggregated by season the individual subsets show opposite trends in (RI) values. Plants most important in summer are triangles and plants most important in winter are squares.

It is worth noting that forty-two of the plants reported during the interviews scored the lowest possible (RI) value. Several of these plants are undocumented in the peer-reviewed literature. These plants, reported one time for the use of one ailment are considered singly reported, each one representing one of the 1674 total responses. Singly reported plants were more frequent in the winter than in the summer, and more frequent in rural as opposed to urban areas (Table 7). The likely explanation is that medicinal plants in general are consumed more in the winter season, a general consensus of all participants and supported by the data; in the summer 127 plants were reported 780 times, while in the winter 146 plants were reported 894 times an increase of 15\% on both accounts. People in rural areas also have access to many more plant species in their fields and around their homes than city dwellers. The largest number of singly reported plants reported by a single family was five, and the most typical response was one. This suggests that there is not a single individual with more expansive or distinct knowledge of medicinal plants, instead exactly half of participant 
Table 7. Number of singly reported responses by season and place of residence.

\begin{tabular}{cccc}
\hline & Summer & Winter & Total \\
\hline Urban & 3 & 6 & 9 \\
Rural & 15 & 18 & 33 \\
Total & 18 & 24 & 42 \\
\hline
\end{tabular}

families were the only ones to apply different, specific bits of knowledge. The singly reported responses reinforce rather than detract from the notion that the population is homogenous in its knowledge. This is important as it indicates that collecting and utilizing local knowledge of plant-based medicines on a broader scale may require a comprehensive community study as was conducted and reported in this study. Studies of other cultures frequently indicate that traditional healers control knowledge and access to plant-based medicines [38] [39] [40] [41]. In those cases, unlike this study, community information about plant-based medicines can be accessed through traditional healers as key providers. The proper method will vary from location to location and researchers should understand the context of their studies.

\section{Conclusions}

This investigation demonstrates the importance of factors beyond knowledge differences and biological properties in shaping plant-based medicine use between an urban and rural population in Eastern Paraguay. While some seasonal differences may be biological, the proximity of the two study sites had similar biological potential. Social factors related to lifestyle and social services explain the biggest differences between rural and urban behavior, while access to wild plants or pharmaceutical medicines explains the urban population's slight preference for pharmaceuticals and the rural population's for plant-based medicine. In situations where social factors did not play a role and access to plant-based medicine was equal between the populations, behavior was essentially the same between the two populations. This was especially true in the use of plants added yerba mate for preventive purposes. The two distinct trends demonstrated by the eighteen most important medicinal plants highlight the importance of the culture of yerba mate tea in the use of medicinal plants. It is impossible to separate yerba mate tea from medicinal plant use. The first is fundamental to Paraguayan cultural identity and the second is a key part of preparing the tea. Therefore, the use of yerba mate tea helps in explaining why there is so much homogeneity between the rural and urban populations concerning plant-based medicine use, and why those practices outlasted urban migration. As long as yerba mate tea remains important culturally in Paraguay, medicinal plant use will continue in all parts of Paraguay.

Our study looked at only a small $7 \mathrm{~km}$ change in location and, in some cases, households that had moved within the previous decade. The physical and temporal changes were small when compared to many other studies. Nonetheless we 
were able to distinguish some differences in the use of plant-based medicine and based upon interviews explain why these differences occurred. Many of our results are similar to other studies in that familiarity with plants and lower costs are important drivers in maintaining use of these traditional medicines. We were also able to compare how plants were acquired and how their use changed seasonally. The daily cultural importance of yerba mate is a distinguishing difference between our study and others. People explicitly stated that the herbs added to yerba mate had preventive or curative value and they associated specific herbs with specific ailments. Because of the importance of yerba mate it may be difficult to extend our results beyond rural and small urban areas in Paraguay but the explicit use of traditional herbal medicine for preventive purposes on a daily basis may be more common in other studies. Most studies seem to focus on curative properties. Preventive medicine merits more study as does an increased emphasis on small-scale studies.

\section{Conflicts of Interest}

The authors declare no conflicts of interest regarding the publication of this paper.

\section{References}

[1] Gaoue, O.G., Coe, M.A., Bond, M., Hart, G., Seyler, B.C. and McMillen, H. (2016) Theories and Major Hypotheses in Ethnobotany. Economic Botany, 71, 269-287. https://doi.org/10.1007/s12231-017-9389-8

[2] Furlan, V., Kujawska, M., Hilgert, N.I. and Pochettino, M.L. (2016) To What Extent Are Medicinal Plants Shared between Country Home Gardens and Urban Ones? A Case Study from Misiones, Argentina. Pharmaceutical Biology, 54, 1628-1640. https://doi.org/10.3109/13880209.2015.1110600

[3] Vandebroek, I. and Balick, M.J. (2012) Globalization and Loss of Plant Knowledge: Challenging the Paradigm. PLos ONE, 7, e37643. https://doi.org/10.1371/journal.pone.0037643

[4] Luján, M.C. and Martínez, G.J. (2017) Dinámica del Conocimiento Etnobotánico en Poblaciones Urbanas y Rurales de Córdoba (Argentina). Boletín Latinoamericano y del Caribe de Plantas Medicinales y Aromáticas, 16, 278-302.

[5] Cerrutti, M. and Bertoncello, R. (2003) Urbanization and Internal Migration Patterns in Latin America. Centro de Estudios de Población. Buenos Aires, Argentina.

[6] Albuquerque, U.P., Soares Silva, J., Almeida Campos, J.L., Silva Sosa, R., Silva, T.C. and Nóbrega Alves, R.R. (2013) The Current Status of Ethnobiological Research in Latin America: Gaps and Perspectives. Journal of Ethnobiology and Ethnomedicine, 9, 72-80. https://doi.org/10.1186/1746-4269-9-72

[7] Cámara-Leret, R., Paniagua-Zambrana, N., Balslev, H. and Macía, M.J. (2014) Ethnobotanical Knowledge Is Vastly Under-Documented in Northwestern South America. PLoS ONE, 9, e85794. https://doi.org/10.1371/journal.pone.0085794

[8] Benítez, B., Bertoni, S., Pérez, S. and González, F. (2008) Principales Especies Medicinales Comercializadas en los Mercados del Departamento de Paraguarí. Diversidad y Determinación de la Importancia Relativa. Rojasiana, 8, 45-61.

[9] Degen, R., Soria, N., Ortiz, M. and Basualdo, I. (2005) Problemática de Nombres 
Comunes de Plantas Medicinales Comercializadas en Paraguay. Dominguezia, 21, 11-16.

[10] González, Y., Mercado, M.I.., Degen, R. and Ponessa, G.I. (2009) Morfoanatomía y Etnobotánica de Rizoma,Ttallo y Escapo de "Kapi’i Kati”, Kyllinga odorata (Cyperaceae) y sus Sustituyentes de Asunción del Paraguay y Alrededores. Lilloa, 46, 58-67.

[11] Li, Y. and Ohizumi, Y. (2004) Search for Constituents with Neurotrophic Factor-Potentiating Activity from the Medicinal Plants of Paraguay and Thailand. The Pharmaceutical Society of Japan, 124, 417-424. https://doi.org/10.1248/yakushi.124.417

[12] Arenas, P. (1987) Medicine and Magic among the Maka Indians of the Paraguayan Chaco. Journal of Ethnopharmacology, 2, 579-295.

https://doi.org/10.1016/0378-8741(87)90104-8

[13] Arenas, P. (2009) Los Estudios sobre Medicina y Farmacopea Vernácula en el Gran Chaco. Rojasiana, 8, 81-100.

[14] Arenas P. and Giberti, G.C. (1987) The Ethnobotany of Odontocarya asarifolia (Menispermaceae), an Edible Plant from the Chaco. Economic Botany, 41, 361-369. https://doi.org/10.1007/BF02859052

[15] Ceuterick, M., Vandebroek, I., Torry, B. and Pieroni, A. (2008) Cross-Cultural Adaptation in Urban Ethnobotany: The Colombian Folk Pharmacopoeia in London. Journal of Ethnopharmacology, 120, 342-359.

https://doi.org/10.1016/j.jep.2008.09.004

[16] Ceuterick, M., Vandebroek, I. and Pieroni, A. (2011) Resilience of Andean Urban Ethnobotanies: A Comparison of Medicinal Plant Use among Bolivian and Peruvian Migrants in the United Kingdom and in Their Countries of Origin. Journal of Ethnopharmacology, 136, 27-54. https://doi.org/10.1016/j.jep.2011.03.038

[17] de Medeiros, P.M., Soldati, G.T., Alencar, N.L., Vendebroaek, I., Pieroni, A., Hanazaki, N. and Albuquerue, U.P. (2012) The Use of Medicinal Plants by Migrant People: Adaptation, Maintenance and Replacement. Evidence-Based Complementary and Alternative Medicine, 2012, Article ID: 807452.

[18] Ellena, R., Quave, C.L. and Pieroni, A. (2012) Comparative Medical Ethnobotany of the Senegalese Community Living in Turin (Northwestern Italy) and in Adeane (Southern Senegal). Evidence-Based Complementary and Alternative Medicine, 2012, Article ID: 604363.

[19] Pieroni, A., Muenz, H., Akbulut, M., Hüsnü Can Başer, K. and Durmuşkahya, C. (2005) Traditional Phytotherapy and Trans-Cultural Pharmacy among Turkish Migrants Living in Cologne, Germany. Journal of Ethnopharmacology, 102, 69-88. https://doi.org/10.1016/j.jep.2005.05.018

[20] Ramzan, S., Soelberg, J., Jäger, A.K. and Cantarero-Arévalo, L. (2017) Traditional Medicine among People of Pakistani Descent in the Capital Region of Copenhagen. Journal of Ethnopharmacology, 196, 267-280. https://doi.org/10.1016/j.jep.2016.11.048

[21] Akbulut, S. and Bayramoglu, M.M. (2014) Reflections of Socio-Economic and Demographic Structure of Urban and Rural on the Use of Medicinal and Aromatic Plants: The Sample of Trabzon Province. Studies on Ethno-Medicine, 8, 89-100. https://doi.org/10.1080/09735070.2014.11886477

[22] van Andel, T. and Carvalheio, L.G. (2013) Why Urban Citizens in Developing Countries Use Traditional Medicines: The Case of Suriname. Evidence-Based Complementary and Alternative Medicine, 2013, Article ID: 687197. 
https://doi.org/10.1155/2013/687197

[23] Sogbohossou, O.E., Achigan-Dako, E.G., Komlan, F.A. and Ahanchede, A. (2015) Diversity and Differential Utilization of Amaranthus spp. along the Urban-Rural Continuum of Southern Benin. Economic Botany, 69, 9-25. https://doi.org/10.1007/s12231-014-9294-3

[24] Yates, S. and Ramírez-Sosa, C.R. (2004) Ethnobotanical Knowledge of Brosimum alicastrum (Moraceae) among Urban and Rural El Salvador Adolescents. Economic Botany, 58, 72-77. https://doi.org/10.1663/0013-0001(2004)058[0072:EKOBAM]2.0.CO;2

[25] Ocvirk, S., Kistler, M., Khan, S., Hayder Talukder, S. and Hauner, H. (2013) Traditional Medicinal Plants Used for the Treatment of Diabetes in Rural and Urban Areas of Dhaka, Bangladesh-An Ethnobotanical Survey. Journal of Ethnobiology and Ethnomedicine, 9, 43.

[26] Heck, C.I. and de Mejia, E.G. (2007) Yerba Mate (Ilex paraguariensis): A Comprehensive Review on Chemistry, Health Implications, and Technological Considerations. Journal of Food Science, 72, 138-151. https://doi.org/10.1111/j.1750-3841.2007.00535.x

[27] Santacruz, R. and Zárate, D. (2015) Vida de la Escuela: Gda Nº 1883 Chamorro Cué Gral. E. Aquino Historia de la Comunidad Plan Anual del Director Año: 1.995.

[28] Hierro, M. (2013) Latin American Migration to Spain: Main Reasons and Future Perspectives. International Migration, 54, 64-83. https://doi.org/10.1111/imig.12056

[29] Parrado, E.A. and Cerrutti, M. (2003) Labor Migrating between Developing Countries: The Case of Paraguay and Argentina. International Migration Review, 37, 101-132. https://doi.org/10.1111/j.1747-7379.2003.tb00131.x

[30] Dirreción General de Estadística, Encuestas y Censos (2015) Paraguay: Proyección de la Población por Sexo y Edad, Según Distrito, 2000-2025: Revisión 2015. Dirreción General de Estadística, Encuestas y Censos, Asunción, 583 p.

[31] International Society of Ethnobiology (2006) International Society of Ethnobiology Code of Ethics (with 2008 Additions). http://ethnobiology.net/code-of-ethics/

[32] Bernard, H.R. (2017) Research Methods in Anthropology. 6th Edition, Rowman and Littlefield, Lanham.

[33] Faul, F., Erdfelder, E., Lang, A.G. and Buchner, A. (2014) GPower: Statistical Power Analysis for Windows and Mac. http://www.gpower.hhu.de

[34] Bennett, B.C. and Prance, G.T. (2000) Introduced Plants in the Indigenous Pharmacopoeia of Northern South America. Economic Botany, 54, 90-102. https://doi.org/10.1007/BF02866603

[35] Garcia, D., Domingues, M.V. and Rodriques, E. (2010) Ethnopharmacological Survey of Migrants Living in the Southeast Atlantic Forest of Diadema, São Paulo, Brazil. Journal of Ethnobiology and Ethnomedicine, 6, 29.

http://www.ethnobiomed.com/content/6/1/29 https://doi.org/10.1186/1746-4269-6-29

[36] Akbulut, S. (2015) Differences in the Traditional Use of Wild Plants between Rural and Urban Areas: The Sample of Adana. Studies on Ethno-Medicine, 9, 141-150. https://doi.org/10.1080/09735070.2015.11905430

[37] Jiang, S. and Quave, C. (2013) A Comparison of Traditional Food and Health Strategies among Taiwanese and Chinese Immigrants in Atlanta, Georgia, USA. Journal of Ethnobiology and Ethnomedicine, 9, 61.

http://www.ethnobiomed.com/content/9/1/61 
https://doi.org/10.1186/1746-4269-9-61

[38] Meissner, O. (2004) The Traditional Healer as Part of the Primary Health Care Team? South African Medical Journal, 94, 901-902.

[39] Tabi, M.M., Powell, M. and Hodnicki, D. (2006) Use of Traditional Healers and Modern Medicine in Ghana. International Nursing Review, 53, 52-58. https://doi.org/10.1111/j.1466-7657.2006.00444.x

[40] Romeiras, M.M., Duarte, M.C., Indjai, B. and Catarino, L. (2012) Medicinal Plants Used to Treat Neurological Disorders in West Africa: A Case Study of Guinea-Bissau. American Journal of Plant Sciences, 3, 1028-1036. https://doi.org/10.4236/ajps.2012.327122

[41] Hirschmann, G.S. and de Arias, A.R. (1990) A Survey of Medicinal Plants in Minas Gerais, Brazil. Journal of Ethnopharmacology, 29, 159-172.

https://doi.org/10.1016/0378-8741(90)90052-U 